\title{
Evaluation of a Reduced Cost Active NDVI Sensor for Crop Nutrient Management
}

\author{
Jared Crain, ${ }^{1}$ Ivan Ortiz-Monasterio, ${ }^{2}$ and Bill Raun ${ }^{1}$ \\ ${ }^{1}$ Department of Plant and Soil Sciences, Oklahoma State University, 044 Agricultural Hall, Stillwater, OK 74078, USA \\ ${ }^{2}$ CIMMYT, Int., Apdo. Postal 6-641, 06600 Mexico City, DF, Mexico
}

Correspondence should be addressed to Bill Raun, bill.raun@okstate.edu

Received 24 July 2012; Accepted 4 December 2012

Academic Editor: Pietro Siciliano

Copyright ( $) 2012$ Jared Crain et al. This is an open access article distributed under the Creative Commons Attribution License, which permits unrestricted use, distribution, and reproduction in any medium, provided the original work is properly cited.

\begin{abstract}
There are methods to increase fertilizer nitrogen use efficiency through optical sensor-based nitrogen application; however, the sensors are expensive and cost prohibitive to farmers in the developing world. This study evaluated a novel, reduced cost, prototype, and optical sensor to determine if it could be used with the same level of accuracy as a commercial sensor. The stability of the prototype sensor (pocket sensor) to maintain an accurate calibration over time, the effect of operator on sensor readings, and sensor performance in maize and wheat were assessed. Evaluation of the sensor performance was conducted in existing wheat and maize trials, as well as turf grass canopies at the International Maize and Wheat Improvement Center, Ciudad Obregon, Mexico.The prototype sensors were highly correlated to the commercial GreenSeeker NDVI sensor in turf grass, wheat, and maize canopies $\left(r^{2}>0.97, r^{2}>0.95\right.$, and $r^{2}>0.91$, resp.). The Pocket Sensors lacked some precision in comparison to the commercial sensor; however, even with the reduced precision, the cost of the sensor and robustness of $N$ fertilizer algorithms compensate for this apparent weakness. The pocket sensor is a new and viable tool to assess wheat and maize nitrogen status and make nitrogen recommendations based upon the data collected with this sensor.
\end{abstract}

\section{Introduction}

Nitrogen is commonly one of the most limiting nutrients in crop production $[1,2]$. Even though nitrogen is often limiting, nitrogen use efficiency (NUE) of applied fertilizer remains low. This is due to several factors including nitrogen run off, leaching, volatilization, and plant losses [3]. Smil [4] reported the world NUE to be close to $50 \%$ while Raun and Johnson [3] reported a value of $33 \%$ for nitrogen use efficiency (NUE) using the formula

$$
\mathrm{NUE}=\frac{(\text { total cereal } N \text { removed })-(N \text { coming from the soil }+N \text { deposited in the rainfall })}{(\text { fertilizer } N \text { applied to cereals })} .
$$

At the time (1999), they showed that a $1 \%$ increase in the NUE is worth more than $\$ 200,000,000$ USD. Regardless of the calculation difference between these two NUE ratios, it can be inferred that NUE is low and can be improved upon and that even small increases in NUE would result in large economic savings.

Combining low NUE rates with the fact that $70 \%$ of the world's nitrogen fertilizer is applied in developing countries [5], there is a large demand to develop methods that can be implemented in diverse regions of the world that will increase NUE, resulting in economic savings and lesser environmental impact. Blackmer et al. [6] suggested that light reflectance could be used to detect nitrogen deficiencies in growing corn leaves. Stone et al. [7] not only documented nitrogen differences in wheat, but also applied variable rate nitrogen based on spectral readings. 
They used a variation of Normalized Difference Vegetative Index (NDVI) and a linear relation with nitrogen content to determine nitrogen fertilizer application rates. This resulted in no difference in yield between variable rate application and the uniform $N$ application; however, there were $N$ savings between 32 and $57 \mathrm{~kg} \mathrm{ha}^{-1}$. Further work by Raun et al. [8] showed that using NDVI values collected during the growing season could be used to predict crop yield potential. This was significant because if crop yield could be accurately predicted, application of nitrogen fertilizer could be tailored for the specific site, reflecting nitrogen status, and need of the crop in order to achieve the estimated yield potential.

Raun et al. [9] published comprehensive work on the Nitrogen Fertilization Optimization Algorithm (NFOA) that included estimated yield potential, Response Index (RI), and coefficient of variation $(\mathrm{CV})$ as a parameter for crop uniformity. Using these methods, Raun et al. [10] showed that NUE in winter wheat was improved by $15 \%$ compared to traditional fertilizer practices. Spectral data has allowed researchers to document maintained crop yields while saving $N$ fertilizer [7], demonstrating that early season $N$ deficiencies could be corrected [11] and that variable rate $N$ management could be used efficiently when $N$ was the limiting factor of crop growth [12].

The use of spectral radiance and the work to develop fertilization algorithms have led the ability to increase NUE. Li et al. [13] documented a 61\% NUE in wheat in China, using $N$ fertilizer recommendations based on using optical sensing and an $N$ fertilization algorithm. This is well above the worldwide NUE of $33 \%$ as documented by Raun and Johnson [3], and this research was conducted in a developing country. The use of optical sensors to manage $N$ should increase around the world because of the benefits that they have shown. One of the main constraints hindering the adoption of this technology is the cost. Current sensors are cost prohibitive to small farmers in the developing world as well as a large number of farmers in the United States. If a small, affordable NDVI sensor could be developed, it would have the potential to drastically improve $N$ fertilizer management practices for farmers in the developed and developing world.

While active sensors to measure NDVI are commercially available, this study specifically focused on the evaluation of an active sensor that would be affordable to developing countries. The objective of this study was to determine if an innovative, smaller, more cost-effective prototype NDVI sensor (OSU NDVI pocket sensor) could be used to duplicate the results of larger commercial NDVI sensors (GreenSeeker). To the authors' knowledge, this is the first study evaluating the performance of a low cost NDVI (pocket sensor) sensor to commercial sensors for $N$ fertilizer management. This work focuses solely on nitrogen assessment using NDVI; however, NDVI has been used for a wide range of crop parameters leaf area index (LAI), photosynthetically active radiation (PAR) [14], and crop yield prediction in wheat, cotton, rice, and maize [15], and the sensor could find applications in these areas as well.

\section{Materials and Methods}

Several field experiments were conducted to compare NDVI readings between the OSU NDVI pocket sensor and the hand held GreenSeeker sensor (Trimble Navigation, Sunnyvale, CA). The GreenSeeker sensor measures normalized difference vegetative index (NDVI) by using a self-illuminated (active sensor) light source in the red and near infrared wavelengths, $(660 \pm 10 \mathrm{~nm})$ and $(780 \pm 15 \mathrm{~nm})$, respectively. The GreenSeeker calculates NDVI using the following formula:

$$
\mathrm{NDVI}=\frac{\left(\rho_{\mathrm{NIR}}-\rho_{\mathrm{red}}\right)}{\left(\rho_{\mathrm{NIR}}+\rho_{\mathrm{red}}\right)},
$$

where $\rho_{\text {NIR }}$ represents the fraction of emitted NIR radiation returned from the sensed area (reflectance) and $\rho_{\text {red }}$ represents the fraction of emitted red radiation from the sensed area (reflectance). The GreenSeeker has an area of measurement of $1 \mathrm{~cm} \times 60 \mathrm{~cm}$ when used in a normal operating range of $60 \mathrm{~cm}$ to $100 \mathrm{~cm}$ over the top of the crop canopy. This sensor collects $>10$ readings per second, and this information is stored in an onboard IPAQ control unit.

The OSU NDVI pocket sensor is also an active sensor that only calculates NDVI. In order to create a reduced cost sensor, the OSU NDVI pocket sensor has some reduced functions in comparison to the GreenSeeker. The sensor uses LED's (light emitting diodes) for its active light source. The red light was centered at $657 \mathrm{~nm}$, and the infrared light was centered at $771 \mathrm{~nm}$ with a full width at half maximum (FWHM) at 20 and $25 \mathrm{~nm}$, respectively. The pocket sensors were then calibrated with the GreenSeeker using a quadratic equation, which adjusted the values of the pocket sensor to display the equivalent GreenSeeker values. The sensor only collects 1 reading per second, and the area of measurement is circular in dimension, and at a height of $60 \mathrm{~cm}$ over the crop canopy it measures an area of $200 \mathrm{~cm}^{2}$. The pocket sensor lacks onboard memory storage, and once a measurement is taken, the screen shows the reading for 2 seconds, and then the data is erased from memory. While the GreenSeeker shows little effect to height and sensor orientation, the pocket sensor readings are significantly affected by height and angle of the sensor. To maintain similar readings all pocket sensor data were taken at a height of $60 \mathrm{~cm}$ above the crop canopy by using a string with attached weight to maintain a uniform height above the canopy. A small bubble level was attached to the sensor, which provided sufficient guidance to maintain the sensor in a nadir position with the ground.

2.1. Reliability of the Sensor Calibration. The first experiments conducted were to evaluate the reliability of the sensor calibration over time. Pocket sensors readings were taken over a six month period in Ciudad Obregon, Sonora, Mexico, to evaluate sensor performance. To evaluate the calibration, pocket sensor and GreenSeeker readings were taken over selected turf grass canopies. The areas measured were small plots that were approximately $1 \mathrm{~m} \times 1 \mathrm{~m}$. GreenSeeker readings were used as the standard value. Each time the calibrations were reviewed, ten locations, representing NDVI values from 0.150 to 0.850 , were used. Three readings were 
taken with the GreenSeeker sensor, and then three readings were taken with each of the pocket sensors. These data were analyzed using a simple linear regression procedure in SAS (2003), for each sensor for the entire trial period and for each measurement event.

2.2. Effect of Operator on Sensor Readings. The pocket sensor is much more susceptible to variations in height and angle. Due to this known variation, trials were conducted to find out what effect the sensor operator might have on the sensor readings. In Ciudad Obregon, readings were collected in existing wheat field trials to determine the amount of operator error in sensor readings. Four beds of wheat $10 \mathrm{~m}$ long were measured for NDVI using two GreenSeeker sensors and three pocket sensors. The NDVI values from GreenSeeker sensors were considered the standard NDVI, and then plots were measured three times with each sensor. Two different operators used all the sensors in each row resulting in a $5 \times 2$ factorial arrangement. These data were analyzed using a SAS generalized linear model. After initial data analysis was completed, selected single degree of freedom contrasts were analyzed to determine differences in sensors and operators. All operators had used the pocket sensor before this data collection and were familiar with the operation of the pocket sensor. Thus, all operators were used to maintaining a uniform height and a nadir view with the ground.

A similar experiment was also conducted using two different pocket sensors and two different operators. In this experiment, the results of the pocket sensors were compared to each other, with no GreenSeeker treatment representing a control NDVI. Data analysis was similar using a general linear model for analysis of variance for a $2 \times 2$ factorial with 8 locations. These experiments tested the effect of operators on sensor readings, and how accurately the pocket sensors could measure NDVI against each other and with different operators.

2.3. Sensor Readings in Maize and Wheat. The pocket sensor was also evaluated in maize in the Yaqui Valley, Sonora, Mexico. Initial data collection showed that a single pocket sensor reading compared to a single GreenSeeker reading in maize did not provide accurate prediction of NDVI. It was determined that by taking three readings with the pocket sensor and using that average as the predicted, NDVI correlated well to the GreenSeeker (data were not shown).

NDVI readings were taken beginning at growth stage V4 [16] and continued until the maize was too tall to take added measurements. Growth stage was recorded for the measurements, and as the maize became too tall, the height of the plot was taken. Height was taken by measuring the height of the whorl, point from which pocket sensor readings were taken from three random plants in each plot. Data were analyzed similar to the calibration stability methods, using simple linear regression to determine the correlation of coefficient between the pocket sensor and GreenSeeker readings.
2.4. Sensor Readings in Wheat. Sensor readings were taken on existing experiments on the CIMMYT experiment station in Ciudad Obregon, Sonora, Mexico. The experiment sight was planted in melgas, a flat planting surface, with eight different durum and eight different bread wheat varieties. There were five different rates of preplant $N$. One variety of bread wheat and one durum were selected for the readings. Sensor readings were taken four times during the growing season corresponding to growth stage Feekes 4-10 [17]. Three pocket sensor readings were taken averaged, and then compared to GreenSeeker readings. Simple linear regression was used to analyze the data, using the same procedure that was used in the calibration stability experiments.

\section{Results}

3.1. Stability of Sensor Calibration. Data were collected to evaluate the stability of the calibration of the pocket sensors. Stability is the ability of the sensor to read the same NDVI's over time. Over the six-month period (December 6, 2010, May 27, 2011), pocket sensor stability was maintained for all sensors, and there was no visible trend of the calibration changing over time. The correlation was extremely high between the pocket sensors and GreenSeeker with coefficients of determination above $r^{2}=0.98$. With this high level of correlation, the pocket sensors accurately predicted NDVI, which is depicted in Figure 1 for a representative pocket sensor, and the other tested 4 sensors exhibited the same results. The pocket sensors did maintain a tight confidence interval with the average interval for the predicted sensor mean being \pm 0.018 and \pm 0.032 for the intercept and the slope, respectively.

Not only was the overall stability excellent, but at each testing date the pocket sensors resulted in equivalent NDVI readings. It was common that the slope and intercept of the pocket sensor compared to the GreenSeeker would vary slightly each time; however, there were no trends to show that the stability of the calibration in the pocket sensor changed or diminished over time. Table 1 shows results representative of one sensor over the test period.

3.2. Effect of Operator on Sensor Readings. Analyses of variance of the two experiments to evaluate the effect of the operator on sensor readings are reported in Tables 2 and 3. Table 2 shows the results of eight different wheat plots using two different pocket sensors and two operators. Five of the eight plots had no significant findings, while two of the plots had a significant interaction between sensor and operator, and one plot had a significant operator effect at the 0.05 significance level. Table 3 shows the results of the effect of different operators and sensors, including both GreenSeeker and pocket sensors. Two rows showed significant interaction between operator and sensor, while the other two rows showed a significant effect for the sensor at alpha $=0.05$ level. The sensor effect could be expected, as the GreenSeeker has more precision than the pocket sensor. Based on these findings, a single degree of freedom contrast was evaluated to compare the two GreenSeeker sensors used 
TABle 1: Calibration stability data for Pocket Sensor \#19, testing that slope intercept $=0$ and slope $=0$ between December 2010 and May 27 , 2011.

\begin{tabular}{|c|c|c|c|c|c|c|c|c|}
\hline Data & $n$ & Sensor & Test variable & Estimate & $r^{2}$ & $\operatorname{Pr}>$ ItI & $\begin{array}{c}\text { Lower } 95 \% \\
\text { confidence limit }\end{array}$ & $\begin{array}{c}\text { Upper 95\% } \\
\text { confidence limit }\end{array}$ \\
\hline 6-Dec-10 & \multirow{2}{*}{6} & 19 & Intercept $=0$ & -0.014 & \multirow{2}{*}{0.987} & 0.140 & -0.032 & 0.005 \\
\hline 6-Dec-10 & & 19 & Slope $=1$ & 1.047 & & 0.030 & 1.005 & 1.090 \\
\hline 14-Dec-10 & \multirow{2}{*}{10} & 19 & Intercept $=0$ & 0.001 & \multirow{2}{*}{0.972} & 0.965 & -0.033 & 0.034 \\
\hline 14-Dec-10 & & 19 & Slope $=1$ & 0.999 & & 0.964 & 0.933 & 1.064 \\
\hline 3-Jan-11 & \multirow{2}{*}{10} & 19 & Intercept $=0$ & -0.082 & \multirow{2}{*}{0.985} & $<.0001$ & -0.113 & -0.050 \\
\hline 3-Jan-11 & & 19 & Slope $=1$ & 1.176 & & $<.0001$ & 1.119 & 1.233 \\
\hline 19-Jan-11 & \multirow{2}{*}{12} & 19 & Intercept $=0$ & -0.014 & \multirow{2}{*}{0.987} & 0.204 & -0.037 & 0.008 \\
\hline 19-Jan-11 & & 19 & Slope $=1$ & 1.059 & & 0.001 & 1.016 & 1.102 \\
\hline $2-F e b-11$ & \multirow{2}{*}{10} & 19 & Intercept $=0$ & -0.060 & \multirow{2}{*}{0.985} & 0.000 & -0.089 & -0.030 \\
\hline 2-Feb-11 & & 19 & Slope $=1$ & 1.093 & & 0.001 & 1.041 & 1.145 \\
\hline 21-Feb-11 & \multirow{2}{*}{10} & 19 & Intercept $=0$ & -0.068 & \multirow{2}{*}{0.983} & $<.0001$ & -0.098 & -0.038 \\
\hline 21-Feb-11 & & 19 & Slope $=1$ & 1.069 & & 0.015 & 1.014 & 1.124 \\
\hline 15-Mar-11 & \multirow{2}{*}{10} & 19 & Intercept $=0$ & -0.043 & \multirow{2}{*}{0.992} & 0.000 & -0.063 & -0.023 \\
\hline 15-Mar-11 & & 19 & Slope $=1$ & 1.082 & & $<.0001$ & 1.044 & 1.119 \\
\hline 1-Apr-11 & \multirow{2}{*}{10} & 19 & Intercept $=0$ & -0.094 & \multirow{2}{*}{0.995} & $<.0001$ & -0.110 & -0.078 \\
\hline 1-Apr-11 & & 19 & Slope $=1$ & 1.161 & & $<.0001$ & 1.129 & 1.193 \\
\hline 15-Apr-11 & \multirow{2}{*}{10} & 19 & Intercept $=0$ & -0.067 & \multirow{2}{*}{0.993} & $<.0001$ & -0.087 & -0.047 \\
\hline 15-Apr-11 & & 19 & Slope $=1$ & 1.106 & & $<.0001$ & 1.070 & 1.143 \\
\hline 27-May-11 & \multirow{2}{*}{10} & 19 & Intercept $=0$ & -0.074 & \multirow{2}{*}{0.980} & 0.000 & -0.110 & -0.039 \\
\hline 27-May-11 & & 19 & Slope $=1$ & 1.136 & & $<.0001$ & 1.073 & 1.199 \\
\hline
\end{tabular}

$n$ : sample size.

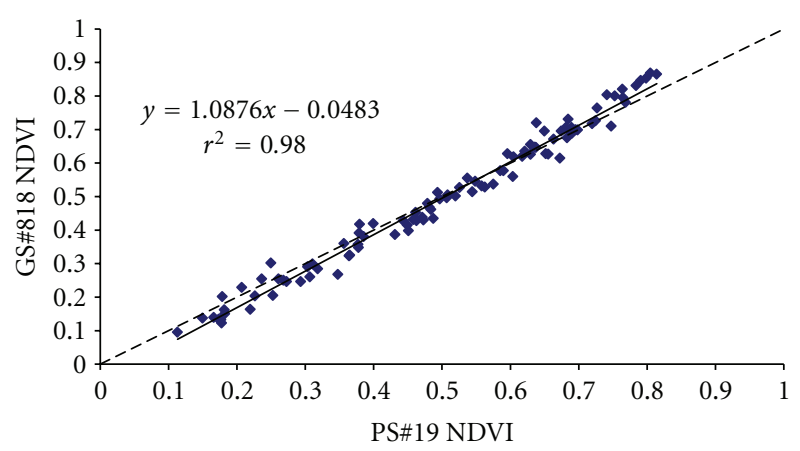

FIGURE 1: Relationship between NDVI sensor readings from pocket sensor\#19 and GreenSeeker\#818, December 2010 through May 2011.

in the experiment. The two GreenSeekers were statistically different from each other in the two rows where a significant sensor by operator interaction occurred.

3.3. Sensor Readings in Maize. The pocket sensor readings in maize for growth stages 4-10 are summarized in Table 4. For growth stages V4-V10, the pocket sensors were highly correlated $\left(r^{2}>0.9\right)$ and performed statistically similar to the GreenSeeker. Data were collected after the V10 growth stage; however, as the maize grows, it becomes more difficult to obtain accurate measurements with the pocket sensors.
Once the plant whorl reached a height of $100 \mathrm{~cm}$, pocket sensor readings diminished in value. This is most likely due to holding the pocket sensor above eye level $(100 \mathrm{~cm}$ to canopy $+60 \mathrm{~cm}$ above the canopy $=160 \mathrm{~cm}$ ) and an inability to hold the sensor level. Growth stage V11 and greater data were not included in the analysis because the best model occurred with V4-V10 data. Figure 2 displays the relationship between a representative pocket sensor and GreenSeeker readings in maize.

3.4. Sensor Readings in Wheat. Table 5 displays the pocket sensor data for wheat in Ciudad Obregon. For all data, both sensors were statistically similar to the GreenSeeker with a slope of 1 and intercept of 0 , respectively. Figure 3 shows a line of best fit and correlation between a representative pocket sensor and GreenSeeker sensors from January 3February 2, 2011, for selected wheat plots. The correlation for all sensors for wheat data $\left(r^{2}>0.95\right)$ was slightly higher than for the maize, which was most likely due to canopy structure differences between wheat and maize.

\section{Discussion}

4.1. Stability of Sensor Calibration. The pocket sensors have good calibration stability. The pocket sensor readings collected over the six-month period in turf grass canopies consistently reproduced similar NDVI values compared to the GreenSeeker. This is an excellent trait for a device that 
TABLE 2: Analysis of variance evaluating sensors and person operating sensors, Ciudad Obregon, Mexico, 2011.

\begin{tabular}{lcccccccc}
\hline Plot & & 2113 & 2114 & 2213 & 2214 & 2313 & 2314 & 2413 \\
& NDVI & NDVI & NDVI & NDVI & NDVI & $\begin{array}{c}2414 \\
\text { NDVI }\end{array}$ & NDVI \\
NDVI
\end{tabular}

${ }^{*}$ Is significant at the alpha $=0.05$ level.

$* *$ Is significant at the alpha $=0.01$ level.

PS: pocket sensor.

SED: Standard error of the difference between two equally replicated means.

C.V.: coefficient of variation.

TABLE 3: Analysis of variance evaluating sensors and person operating sensors, Ciudad Obregon, Mexico, 2011.

\begin{tabular}{|c|c|c|c|c|c|}
\hline \multirow{2}{*}{ Plot } & & Row 1 & Row 2 & Row 3 & Row 4 \\
\hline & & NDVI & NDVI & NDVI & NDVI \\
\hline Source of Variation & $\mathrm{df}$ & \multicolumn{4}{|c|}{ Mean square error } \\
\hline Operator & 1 & 0.00065 & 0.000154 & 0.017579 & 0.00001 \\
\hline Sensor & 4 & $0.00771^{* *}$ & 0.017572 & 0.012687 & $0.00261^{* *}$ \\
\hline Person * Sensor & 4 & 0.00031 & $0.00113^{*}$ & $0.00153^{* *}$ & 0.00051 \\
\hline Residual Error & 50 & 0.00041 & 0.000434 & 0.000255 & 0.00069 \\
\hline SED & & 0.012 & 0.012 & 0.009 & 0.015 \\
\hline C.V. & & 3.5 & 4.4 & 2.9 & 5.5 \\
\hline$r^{2}$ & & 0.617 & 0.776 & 0.854 & 0.267 \\
\hline Treatment & & \multicolumn{4}{|c|}{ Treatment means } \\
\hline PS\#20 Person 1 & & 0.596 & 0.522 & 0.601 & 0.503 \\
\hline PS\#20 Person 2 & & 0.604 & 0.518 & 0.558 & 0.483 \\
\hline PS\#32 Person 1 & & 0.617 & 0.497 & 0.597 & 0.486 \\
\hline PS\#32 Person 2 & & 0.616 & 0.495 & 0.575 & 0.500 \\
\hline PS\#37 Person 1 & & 0.553 & 0.425 & 0.567 & 0.454 \\
\hline PS\#37 Person 2 & & 0.576 & 0.461 & 0.498 & 0.464 \\
\hline GS\#96 Person 1 & & 0.557 & 0.434 & 0.525 & 0.471 \\
\hline GS\#96 Person 2 & & 0.556 & 0.418 & 0.498 & 0.471 \\
\hline GS\#97 Person 1 & & 0.568 & 0.471 & 0.539 & 0.480 \\
\hline GS\#97 Person 2 & & 0.572 & 0.473 & 0.529 & 0.482 \\
\hline Contrast GS\#96 = GS\#97 & & ns & $* *$ & $* *$ & $\mathrm{~ns}$ \\
\hline
\end{tabular}

* Is significant at the alpha $=0.05$ level.

$* *$ Is significant at the alpha $=0.01$ level.

PS: pocket sensor.

GS: GreenSeeker sensor.

ns: not significant.

SED: standard error of the difference between two equally replicated means.

C.V.: coefficient of variation. 
TABLE 4: Simple linear regression between pocket sensors (PSs) and GreenSeeker sensors, V4-V10 growth stages in maize, Ciudad Obregon, Mexico, 2011.

\begin{tabular}{|c|c|c|c|c|c|c|c|c|}
\hline Sensor & Crop & $n$ & Test variable & $r^{2}$ & Estimate & $\operatorname{Pr}>$ ItI & $\begin{array}{c}\text { Lower 95\% } \\
\text { confidence limit }\end{array}$ & $\begin{array}{c}\text { Upper } 95 \% \\
\text { confidence limit }\end{array}$ \\
\hline PS\#37 & Maize & \multirow{2}{*}{289} & Intercept $=0$ & \multirow{2}{*}{0.912} & 0.010 & 0.236 & -0.006 & 0.025 \\
\hline PS\#37 & Maize & & Slope =1 & & 0.995 & 0.787 & 0.960 & 1.031 \\
\hline PS\#27 & Maize & \multirow{2}{*}{95} & Intercept $=0$ & \multirow{2}{*}{0.913} & -0.015 & 0.315 & -0.043 & 0.014 \\
\hline PS\#27 & Maize & & Slope $=1$ & & 1.044 & 0.188 & 0.978 & 1.111 \\
\hline
\end{tabular}

Pocket sensor: independent variable. GreenSeeker: dependent variable. $n$ : sample size.

TABLE 5: Simple linear regression between the pocket sensors (PSs) and GreenSeeker in wheat, Ciudad Obregon, Mexico, 2011.

\begin{tabular}{lcccccccc}
\hline Sensor & Crop & $n$ & Test variable & $r^{2}$ & Estimate & Pr > ItI & $\begin{array}{c}\text { Lower 95\% } \\
\text { confidence limit }\end{array}$ & $\begin{array}{c}\text { Upper 95\% } \\
\text { confidence limit }\end{array}$ \\
\hline 20 & All wheat data & \multirow{2}{*}{80} & Intercept & 0.964 & 0.020 & 0.203 & -0.011 & 0.051 \\
20 & All wheat data & & Slope & & 0.994 & 0.774 & 0.950 & 1.037 \\
32 & All wheat data & \multirow{2}{*}{60} & Intercept & 0.955 & 0.008 & 0.673 & -0.031 & 0.048 \\
32 & All wheat data & & Slope & & 0.998 & 0.958 & 0.942 & 1.055 \\
\hline
\end{tabular}

Pocket sensor: independent variable. GreenSeeker: dependent variable. $n$ : sample size.

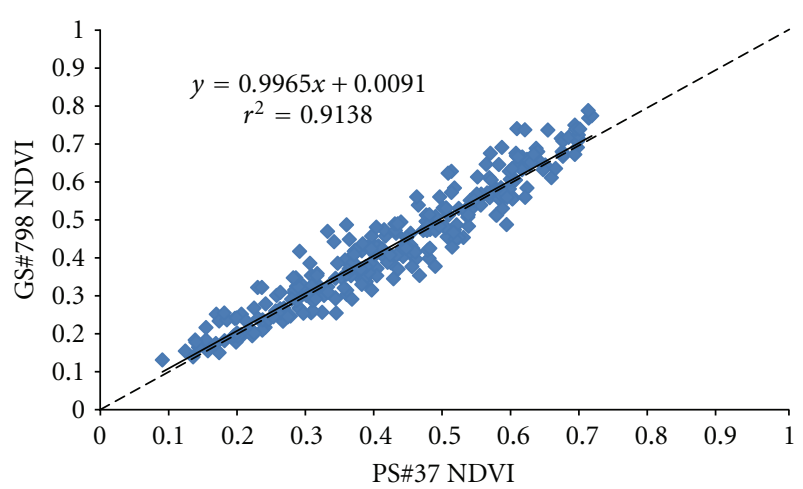

FIGURE 2: Relationship between pocket sensor\#37 and GreenSeeker\#798 NDVI readings in maize V4-V10 growth stages, Ciudad Obregon, Mexico, 2011.

is being manufactured for the developing countries. The stability displayed by the pocket sensor would allow for an initial calibration to be made, and then the pocket sensors could be used for extended periods of time without being concerned about the quality of readings. Over the period of testing, the sensors were used extensively, the battery was allowed to be dissipated, charged, and used again, and the stability of readings remained constant.

Some variation in the stability data was found; however, it probably represents minor effects of the operator and the ability to accurately measure a canopy with both the GreenSeeker and pocket sensors. Even with these limitations, the tested five pocket sensors performed on average NDVI \pm 0.02 of GreenSeeker. This was determined by using the upper and lower $95 \%$ regression estimates and determining

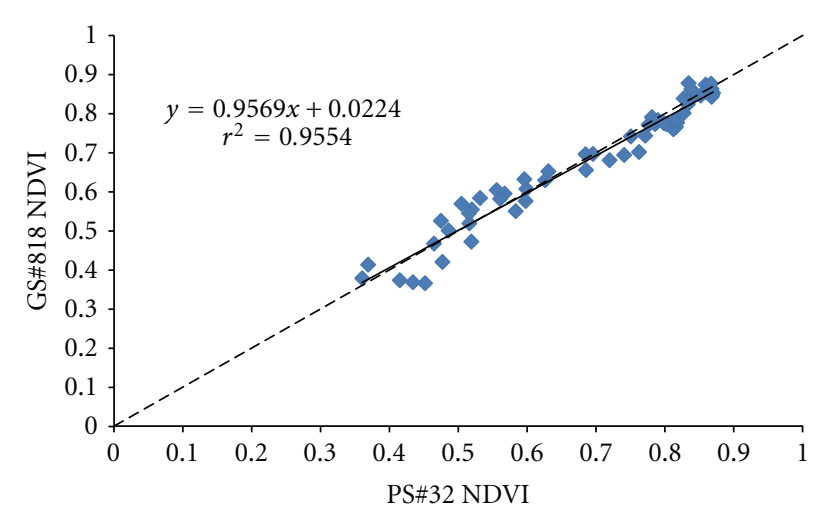

Figure 3: Relationship between pocket sensor\#32 and GreenSeeker\#818 NDVI readings for wheat growth stage Feekes 4-10, Ciudad Obregon, Mexico, 2011, January 3-February 2, 2011.

how the pocket sensor NDVI (95\% confidence level) would deviate from a control value (Table 6).

4.2. Effect of Operator on Sensor Readings. Tests designed to determine the effect of the operator on sensor readings showed some significant differences between sensors and operators and well as sensor by operator interaction. However, upon inspection of the data, much of this variation was small, when using a trained operator. A trained operator is considered someone who knows that the pocket sensor can be affected by differences in height above the canopy and angle of view, in addition to having some ( $>30$ minutes) operating experience with the sensor. Both height and sensor angle can affect readings, but sensor angle probably has the most impact because height was controlled using a $60 \mathrm{~cm}$ 
TABLE 6: Pocket sensor NDVI values based on 95\% confidence levels for turf grass, wheat, and maize canopies.

\begin{tabular}{|c|c|c|c|c|c|c|c|c|c|c|c|c|c|}
\hline Sensor & Crop & Type estimate & $\begin{array}{c}\text { Pred. } \\
\text { NDVI } \\
0.4\end{array}$ & $\begin{array}{l}\text { Range } \\
\text { NDVI }\end{array}$ & $\begin{array}{c}\text { Pred. } \\
\text { NDVI } \\
0.5\end{array}$ & $\begin{array}{l}\text { Range } \\
\text { NDVI }\end{array}$ & $\begin{array}{c}\text { Pred. } \\
\text { NDVI } \\
0.6\end{array}$ & $\begin{array}{l}\text { Range } \\
\text { NDVI }\end{array}$ & $\begin{array}{c}\text { Pred. } \\
\text { NDVI } \\
0.7\end{array}$ & $\begin{array}{l}\text { Range } \\
\text { NDVI }\end{array}$ & $\begin{array}{c}\text { Pred. } \\
\text { NDVI } \\
0.8\end{array}$ & $\begin{array}{l}\text { Range } \\
\text { NDVI }\end{array}$ & $\begin{array}{l}\text { Mean NDVI } \\
\text { by sensor }\end{array}$ \\
\hline 19 & Grass & Average & 0.388 & & 0.497 & & 0.605 & & 0.713 & & 0.821 & & \\
\hline 19 & Grass & 95\% extreme & 0.372 & 0.016 & 0.479 & 0.018 & 0.585 & 0.020 & 0.691 & 0.022 & 0.797 & 0.023 & 0.020 \\
\hline 20 & Grass & Average & 0.402 & & 0.505 & & 0.607 & & 0.710 & & 0.812 & & \\
\hline 20 & Grass & 95\% extreme & 0.388 & 0.014 & 0.489 & 0.016 & 0.589 & 0.018 & 0.690 & 0.019 & 0.791 & 0.021 & 0.018 \\
\hline 27 & Grass & Average & 0.401 & & 0.508 & & 0.614 & & 0.721 & & 0.828 & & \\
\hline 27 & Grass & 95\% extreme & 0.386 & 0.015 & 0.491 & 0.017 & 0.596 & 0.018 & 0.701 & 0.020 & 0.807 & 0.022 & 0.018 \\
\hline 32 & Grass & Average & 0.398 & & 0.499 & & 0.599 & & 0.700 & & 0.800 & & \\
\hline 32 & Grass & 95\% extreme & 0.382 & 0.016 & 0.481 & 0.018 & 0.580 & 0.019 & 0.679 & 0.021 & 0.777 & 0.023 & 0.019 \\
\hline 37 & Grass & Average & 0.403 & & 0.507 & & 0.610 & & 0.713 & & 0.816 & & \\
\hline 37 & Grass & 95\% extreme & 0.388 & 0.016 & 0.489 & 0.018 & 0.590 & 0.019 & 0.692 & 0.021 & 0.793 & 0.023 & 0.019 \\
\hline 27 & Maize & Average & 0.403 & & 0.507 & & 0.611 & & 0.716 & & 0.820 & & \\
\hline 27 & Maize & 95\% extreme & 0.348 & 0.054 & 0.446 & 0.061 & 0.544 & 0.068 & 0.642 & 0.074 & 0.739 & 0.081 & 0.068 \\
\hline 37 & Maize & Average & 0.408 & & 0.508 & & 0.607 & & 0.707 & & 0.806 & & \\
\hline 37 & Maize & 95\% extreme & 0.378 & 0.030 & 0.474 & 0.034 & 0.570 & 0.037 & 0.666 & 0.041 & 0.762 & 0.044 & 0.037 \\
\hline 20 & Wheat & Average & 0.418 & & 0.517 & & 0.616 & & 0.716 & & 0.815 & & \\
\hline 20 & Wheat & 95\% extreme & 0.369 & 0.049 & 0.464 & 0.053 & 0.559 & 0.057 & 0.654 & 0.062 & 0.749 & 0.066 & 0.057 \\
\hline 32 & Wheat & Average & 0.403 & & 0.502 & & 0.601 & & 0.700 & & 0.798 & & \\
\hline 32 & Wheat & 95\% extreme & 0.346 & 0.057 & 0.440 & 0.062 & 0.534 & 0.067 & 0.628 & 0.071 & 0.723 & 0.076 & 0.067 \\
\hline
\end{tabular}

Pred. NDVI: Predicted NDVI based on pocket sensor reading.

Range NDVI: NDVI difference from average predicted value.

Type estimate: average: average value based on pocket sensor calibration.

95\% extreme: the most extreme value displayed by the pocket sensor with $95 \%$ confidence limit.

string. Angle was controlled using a bubble level; however, when operators initially took readings, it was challenging for them to maintain the sensor and walk over the crop canopy. This problem was easily corrected with operating experience, and most operators after a short time (30 minutes) could take reproducible results. In the eight wheat plots where pocket sensors were compared, only one sensor comparison differed by more than 0.03 NDVI. From the stability data, the accuracy of the pocket sensor is \pm 0.02 NDVI, along with the SED (standard error of the difference of two equally replicated means) being approximately 0.012 . With the known error in NDVI readings, it is not surprising to find data such as these, and further analysis of small difference in NDVI is discussed.

In the four rows where NDVI was read with three pocket sensors and two GreenSeeker sensors, there was a significant interaction between sensors and operators in two rows. The other two rows showed a significant effect for sensor. The effect of sensor should be expected as the GreenSeeker is slightly more precise, and the pocket sensor measures \pm 0.02 NDVI as measured by the GreenSeeker.

Even with the differences that were observed, the data show that different operators can obtain similar results. This is extremely important for the pocket sensor especially if it is to be mass produced and there will be many operators. To obtain similar results, the operators should be trained and take sufficient amounts of data so that they are comfortable and confident using the pocket sensors. This training will help insure that the $N$ fertilizer recommendations made by any operator are accurate.

4.3. Sensor Readings in Maize. The pocket sensors performed well in maize. By evaluating the confidence intervals and predicted NDVI's, maize readings should include an adjustment that is wider than readings over grass canopies. The average sensor reading in maize is NDVI \pm 0.05 (Table 6). This adjustment is reasonable because of the difference in canopy architecture. In grass readings, the canopy was enclosed and uniform; however, in maize, the plants grow up and there is space between the plants. This space and failure of the canopy to be completely closed probably results in the poorer correlation at young vegetative stages V4. Even though, the V4 data were not highly correlated $\left(r^{2}=0.32\right.$ compared to later growth stages $r^{2}>0.8$ ), the graph of these data were close to the expected values. Correlation was likely low due to the early growth stage and lack of early nitrogen stress. Beginning at V5 and later vegetative stages, the correlation and model improved most likely due to a more uniform canopy. Raun et al. [18] reported that the greatest variation occurred at V6, and as the canopy closed, the coefficient of variation (C.V.) among data readings decreased. Sensor readings were taken after growth stage V10; however, the models for these data were less accurate than data between V4 and V10. Similar to the problem of a developed canopy, 
TABLE 7: Changes in nitrogen recommendations from varying NDVI values. Nitrogen recommendations were made from the sensor-based nitrogen rate calculator (http://www.soiltesting.okstate.edu/SBNRC/SBNRC.php) accessed March 10, 2011.

\begin{tabular}{|c|c|c|c|c|c|c|c|c|c|c|c|}
\hline Crop & Farmer practice & $\begin{array}{c}\quad N \\
\text { rich strip }\end{array}$ & $\begin{array}{c}N \\
\text { recommendations }\end{array}$ & $+0.025 \mathrm{NDVI}$ & $\Delta N$ & -0.025 NDVI & $\Delta N$ & $+0.05 \mathrm{NDVI}$ & $\Delta N$ & -0.05 NDVI & $\Delta N$ \\
\hline Wheat* & 0.8 & 0.83 & 7.6 & 0 & -7.6 & 14.8 & 7.2 & 0 & -7.6 & 21.8 & 14.2 \\
\hline Wheat* & 0.625 & 0.83 & 54.2 & 47.9 & -6.3 & 60.3 & 6.1 & 41.6 & -12.6 & 66.5 & 12.3 \\
\hline Wheat* & 0.45 & 0.83 & 59 & 54.9 & -4.1 & 63.3 & 4.3 & 85.5 & 26.5 & 67.9 & 8.9 \\
\hline Wheat* & 0.6 & 0.65 & 12.4 & 5.7 & -6.7 & 18.9 & 6.5 & 0 & -12.4 & 25.4 & 13 \\
\hline Wheat* & 0.5 & 0.65 & 38.4 & 31.9 & -6.5 & 45 & 6.6 & 25.4 & -13 & 51.8 & 13.4 \\
\hline \multicolumn{5}{|c|}{ Average recommended difference } & -6.24 & & 6.14 & & -3.82 & & 12.36 \\
\hline Maize** & 0.8 & 0.83 & 25.9 & 19.1 & -6.8 & 32.3 & 6.4 & 12.1 & -13.8 & 38.5 & 12.6 \\
\hline Maize** & 0.625 & 0.83 & 66.8 & 61.3 & -5.5 & 72.1 & 5.3 & 55.8 & -11 & 77.5 & 10.7 \\
\hline Maize** & 0.45 & 0.83 & 70.6 & 74.5 & 3.9 & 66.9 & -3.7 & 78.6 & 8 & 63.4 & -7.2 \\
\hline Maize** & 0.6 & 0.65 & 24.2 & 18.2 & -6 & 30 & 5.8 & 12.1 & -12.1 & 35.8 & 11.6 \\
\hline Maize $^{* *}$ & 0.5 & 0.65 & 47.4 & 41.6 & -5.8 & 53.3 & 5.9 & 35.8 & -11.6 & 59.3 & 11.9 \\
\hline \multicolumn{5}{|c|}{ Average recommended difference } & -4.04 & & 3.94 & & -8.1 & & 7.92 \\
\hline
\end{tabular}

$\Delta N$ : difference in nitrogen recommendation based on change in NDVI value.

${ }^{*} N$ recommendations determined for wheat at normal planting time sensed at the 1st week of March. $N$ rich strip and farmer values are a range of what would normally be encountered in the field.

** $N$ recommendations determined for corn with a normal planting date sensed during the 2 nd week of June. $N$ rich strip and farmer values show both representative and extreme values found in the field.

once the maize neared V12, there were problems taking readings due to the height of the plant. While this could be a concern as far as the utility of the pocket sensor, accurate data collection was maintained to growth stage V10. Scharf et al. [19] noted that most top dress fertilizer applications occur before V8 because no special equipment is needed. After V8, it is likely that high clearance equipment will be needed to avoid damaging the maize, and this equipment is not readily available in developing countries.

4.4. Sensor Readings in Wheat. The pocket sensor readings in wheat were highly correlated to the GreenSeeker. Based on confidence intervals, the accuracy of the pocket sensors was NDVI \pm 0.06 . Correlations between the pocket sensors and the GreenSeeker were higher in wheat than in maize. This is probably due to the short well-closed canopy that wheat develops compared to maize.

4.5. Significance of Findings. While the GreenSeeker and pocket sensors were similar, they were often significantly different at the alpha $=0.05$ level. The GreenSeeker is built for precision, and the precision effects the cost of the sensor. The pocket sensor has been designed to mimic the same results, but at approximately one tenth the cost. Many of the pocket sensors had 95\% confidence levels within the GreenSeeker levels, and several that were significantly different were different at small values of NDVI. With the ultimate goal of the pocket sensor to increase NUE in developing countries and return economic profit to farmers, what does a 0.02 or 0.05 NDVI difference signify? Nitrogen rates are based upon a reference strip, nonnitrogen limiting area, and the comparison to the farmer's field as summarized by Raun et al. [9]. Table 7 made using the sensor-based nitrogen rate calculator (http://
www.soiltesting.okstate.edu/SBNRC/SBNRC.php) show the difference in nitrogen recommendation rates for several NDVI values for both corn and wheat. Assuming that the pocket sensor can accurately read \pm 0.02 NDVI, $N$ recommendations would only vary within $\pm 4-6 \mathrm{~kg} \mathrm{~N} \mathrm{ha}^{-1}$ of the actual rate for corn and wheat, respectively. Even at $\pm 0.05 \mathrm{NDVI}$, the recommended nitrogen would vary from the needed $N$ rate by $\pm 8-12 \mathrm{~kg} \mathrm{Nha}^{-1}$ for corn and wheat, respectively. Lawrence and Yule (2007) [20] reported that urea application was $\pm 5 \mathrm{~kg} \mathrm{Nha}^{-1}$ within the targeted application rate only $24 \%$ of the time using a disc spreader. Thus, a recommended rate from the pocket sensor, even with small errors, would usually be sufficiently close to the required rate that application error and other environmental variables could have more effect on crop growth than the amount of fertilizer recommended.

4.6. Recommendations for Using the Pocket Sensor for $N$ Application. Based on the results of this research, the pocket sensor should have excellent utility in making nitrogen recommendations. The pocket sensor lacks some precision compared to the GreenSeeker; however, adequate steps could be taken to overcome this limitation. The most probable would be to use the known accuracy and adjust pocket sensor readings accordingly. For $N$ applications, this may entail adding accuracy (+0.025 and +0.03 for maize and wheat, resp.) to the $N$ rich strip portion of the field while subtracting the same level of accuracy from the farmer practice. The readings from the $N$ rich strip and farmer practice should be the average of three readings over each respective area, similar to the way data were collected for this study. This method will nearly always result in some fertilizer application, but any attempt to better manage fertilizer in 
the developing or developed world has to strike a balance between $N$ to meet crop needs and enough $N$ to reach maximum economic productivity while not resulting in increased environmental risk. Any method that underapplies $N$ and results in lost economic productivity will not find acceptance among farmers. In many high input, intensive agricultural areas in the developing world, often excess $N$ is more of an issue than deficient $N$. For example, OrtizMonasterio and Raun [21] found reduced $N$ application and increased farmer profits in the Yaqui Valley by using sensorbased nitrogen management. Using GreenSeeker sensors, the average rate of $N$ application was $69 \mathrm{~kg} \mathrm{~N} \mathrm{ha}^{-1}$ less than that of the farmer practice.

Using the previous method should result in reasonable fertilizer recommendations. Under the worst case scenario, if an actual $N$ rich strip reading was NDVI -0.06 (full value of the known accuracy) and the farmer practice was NDVI+0.06, using the described method would result in a "miss" of the accurate recommendations by $0.06 \mathrm{NDVI}$ or approximately $12 \mathrm{~kg} \mathrm{Nha}^{-1}$. While this would result in lower crop yield, this is an extreme example of the pocket sensor reading two plots at the most extreme values. While this is possible, this can be avoided by training because an actual 1.2 NDVI difference should be visible to the human eye. The opposite of this scenario calls for added and excess $N$, which would not result in reduced yields. In intensively managed areas, like the Yaqui Valley, the extra $N$ may still be less than what the farmer would traditionally apply [21]. The pocket sensor lacks some of the precision of the GreenSeeker; however, this precision was made up for the reduced cost of the sensor. While precision could be increased in the pocket sensor by using more precise components, the added cost would make the sensor more expensive and thus less likely to be used in developing countries. The mass production of this sensor and its adoption in the developing and developed world has the potential to increase farmer economic productivity and reduce the environmental problems associated with excess $N$ fertilization.

\section{Conflict of Interests}

The mention of any trademarked equipment is for research purposes only. The authors have no direct financial relation with any of the named equipment manufactures.

\section{Acknowledgments}

This research was made possible by the United States Fulbright Program and was supported by the International Maize and Wheat Improvement Center (CIMMYT). The help and support of the Nutrients Program staff at CIMMYT is greatly appreciated.

\section{References}

[1] K. Girma, S. Holtz, B. Tubaña, J. Solie, and W. Raun, "Nitrogen accumulation in shoots as a function of growth stage of corn and winter wheat," Journal of Plant Nutrition, vol. 34, no. 2, pp. 165-182, 2011.

[2] A. R. Szumigalski and R. C. Van Acker, "Nitrogen yield and land use efficiency in annual sole crops and intercrops," Agronomy Journal, vol. 98, no. 4, pp. 1030-1040, 2006.

[3] W. R. Raun and G. V. Johnson, "Improving nitrogen use efficiency for cereal production," Agronomy Journal, vol. 91, no. 3, pp. 357-363, 1999.

[4] V. Smil, "Nitrogen in crop production: an account of global flows," Global Biogeochemical Cycles, vol. 13, no. 2, pp. 647662, 1999.

[5] P. Heffer and M. Prud'homme, "World agriculture and fertilizer demand, global fertilizer supply and trade 20072008," in Proceedings of the 33rd IFA Enlarged Council Meeting, Doha, Qatar, 2007.

[6] T. M. Blackmer, J. S. Schepers, and G. E. Varvel, "Light reflectance compared with other nitrogen stress measurements in corn leaves," Agronomy Journal, vol. 86, no. 6, pp. 934-938, 1994.

[7] M. L. Stone, J. B. Solie, W. R. Raun, R. W. Whitney, S. L. Taylor, and J. D. Ringer, "Use of spectral radiance for correcting in-season fertilizer nitrogen deficiencies in winter wheat," Transactions of the American Society of Agricultural Engineers, vol. 39, no. 5, pp. 1623-1631, 1996.

[8] W. R. Raun, J. B. Solie, G. V. Johnson et al., "In-season prediction of potential grain yield in winter wheat using canopy reflectance," Agronomy Journal, vol. 93, no. 1, pp. 131138, 2001.

[9] W. R. Raun, J. B. Solie, M. L. Stone et al., "Optical sensor-based algorithm for crop nitrogen fertilization," Communications in Soil Science and Plant Analysis, vol. 36, no. 19-20, pp. 27592781, 2005.

[10] W. R. Raun, J. B. Solie, G. V. Johnson et al., "Improving nitrogen use efficiency in cereal grain production with optical sensing and variable rate application," Agronomy Journal, vol. 94, no. 4, pp. 815-820, 2002.

[11] G. E. Varvel, J. S. Schepers, and D. D. Francis, "Ability for in-season correction of nitrogen deficiency in corn using chlorophyll meters," Soil Science Society of America Journal, vol. 61, no. 4, pp. 1233-1239, 1997.

[12] E. Zillmann, S. Graeff, J. Link, W. D. Batchelor, and W. Claupein, "Assessment of cereal nitrogen requirements derived by optical on-the-go sensors on heterogeneous soils," Agronomy Journal, vol. 98, no. 3, pp. 682-690, 2006.

[13] F. Li, Y. Miao, F. Zhang et al., "In-season optical sensing improves nitrogen-use efficiency for winter wheat," Soil Science Society of America Journal, vol. 73, no. 5, pp. 1566-1574, 2009.

[14] R. B. Myneni, "Estimation of global leaf area index and absorbed par using radiative transfer models," IEEE Transactions on Geoscience and Remote Sensing, vol. 35, no. 6, pp. 1380-1393, 1997.

[15] N. A. Quarmby, M. Milnes, T. L. Hindle, and N. Silleos, “The use of multi-temporal NDVI measurements from AVHRR data for crop yield estimation and prediction," International Journal of Remote Sensing, vol. 14, no. 2, pp. 199-210, 1993.

[16] S. W. Ritchie, J. J. Hanway, and G. O. Benson, How a Corn Plant Develops, SR-48, Iowa State University Cooperative Extension Service, Ames, Iowa, USA, 1996.

[17] E. C. Large, "Growth stages in cereals, illustration of the Feekes scale," Plant Pathology, vol. 3, pp. 128-129, 1954.

[18] W. R. Raun, J. B. Solie, K. L. Martin et al., "Growth stage, 
development, and spatial variability in corn evaluated using optical sensor readings," Journal of Plant Nutrition, vol. 28, no. 1, pp. 173-182, 2005.

[19] P. C. Scharf, W. J. Wiebold, and J. A. Lory, "Corn yield response to nitrogen fertilizer timing and deficiency level," Agronomy Journal, vol. 94, no. 3, pp. 435-441, 2002.

[20] H. G. Lawrence and I. J. Yule, "Estimation of the in-field variation in fertiliser application," New Zealand Journal of Agricultural Research, vol. 50, no. 1, pp. 25-32, 2007.

[21] J. I. Ortiz-Monasterio and W. Raun, "Reduced nitrogen and improved farm income for irrigated spring wheat in the Yaqui Valley, Mexico, using sensor based nitrogen management," Journal of Agricultural Science, vol. 145, pp. 1-8, 2007. 

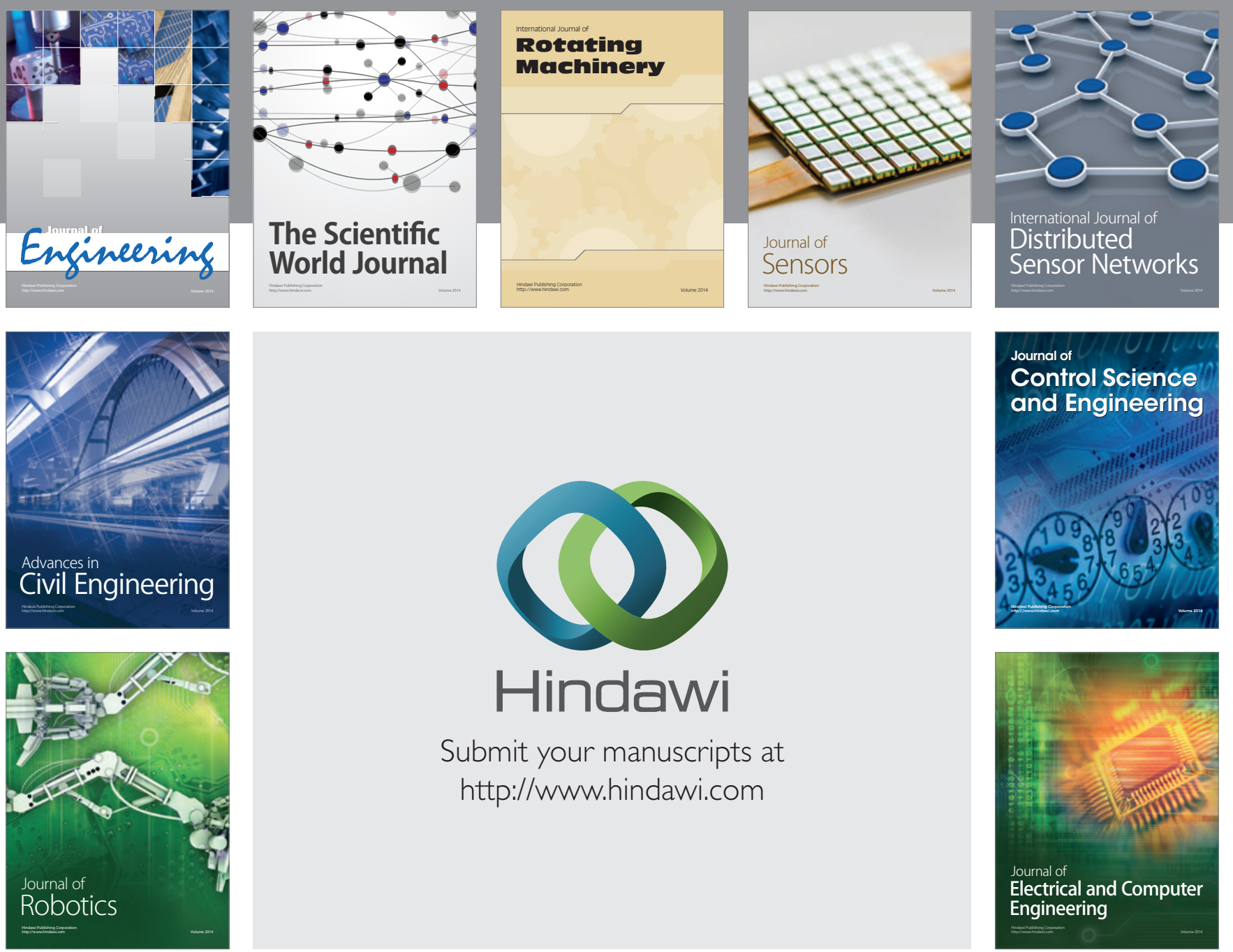

Submit your manuscripts at

http://www.hindawi.com
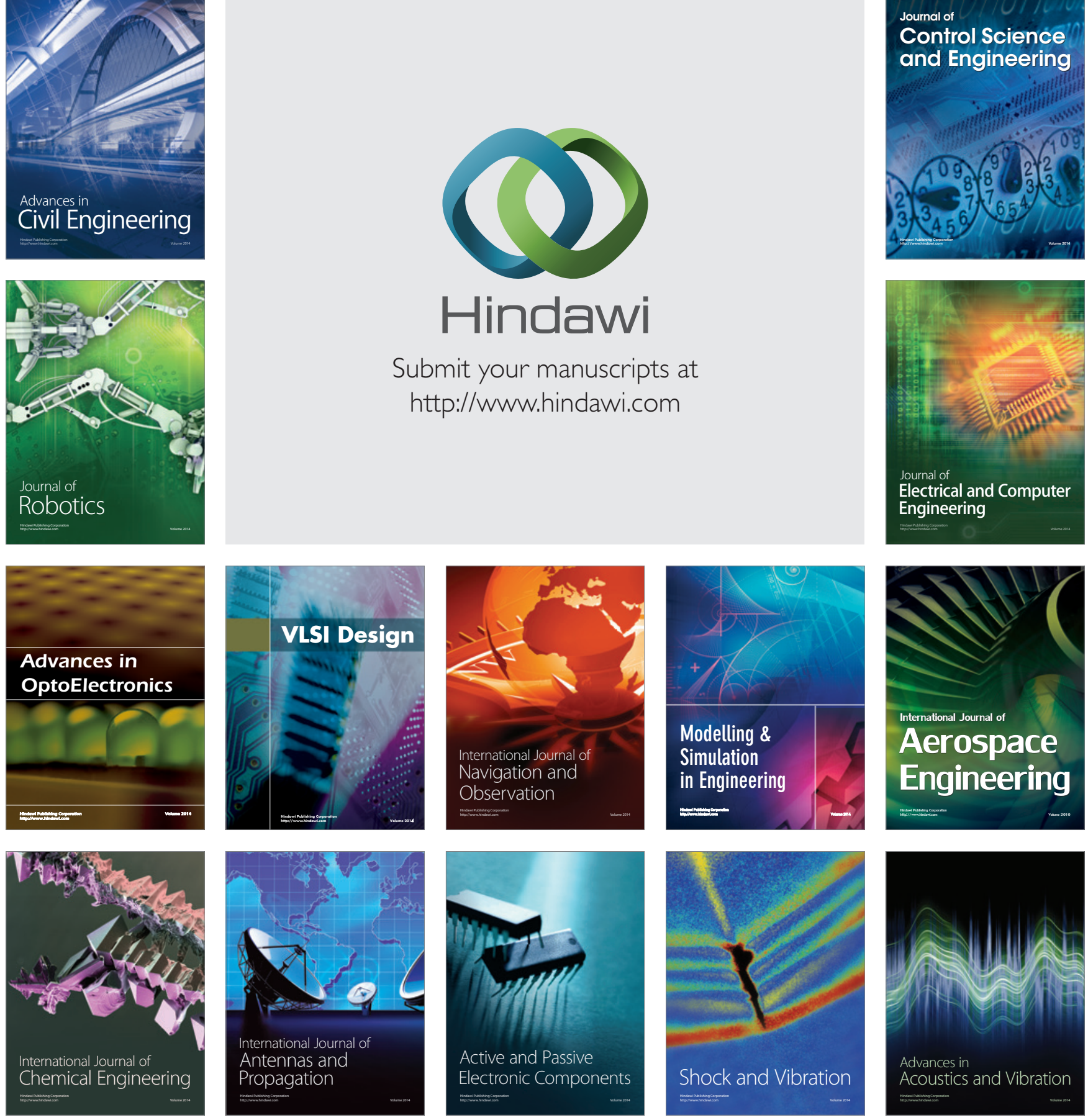